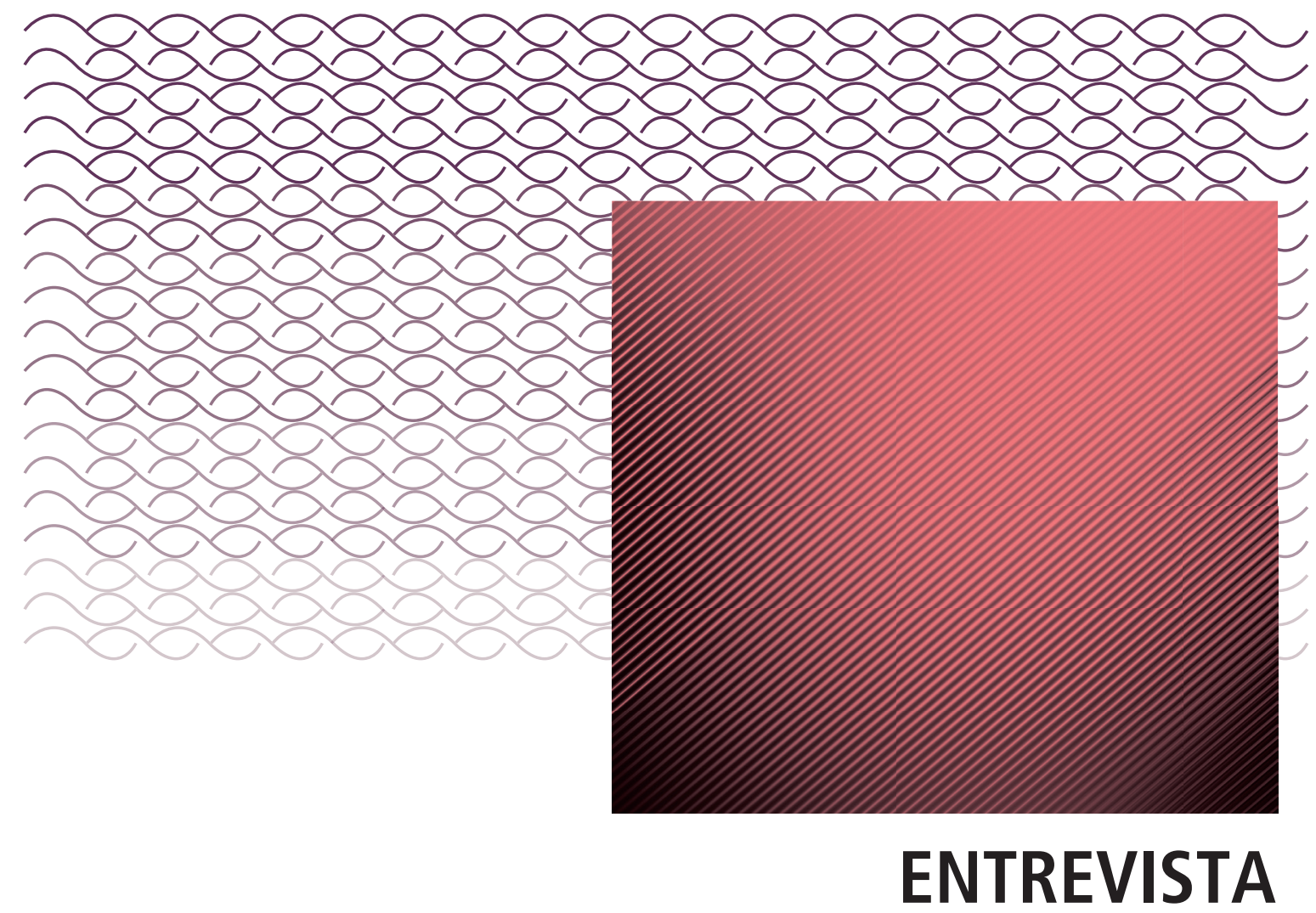




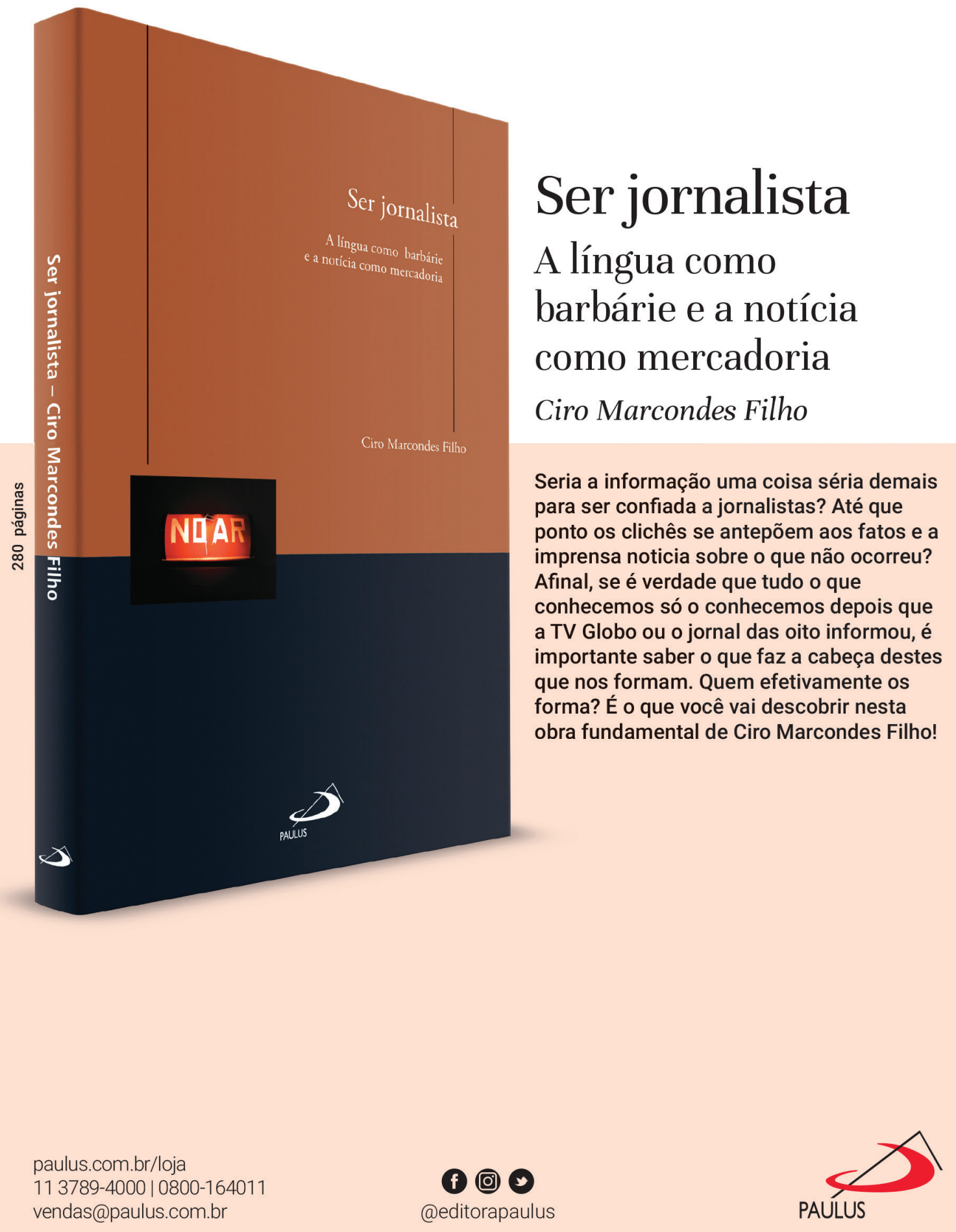




\title{
Flusser com espanto
}

\author{
Flusser with astonishment \\ Flusser con asombro
}

\section{Entrevista com Erick Felinto}

\author{
Realizada por Elinaldo S. Meira \\ Faculdade Paulus de Tecnologia e Comunicação - FAPCOM \\ <elinaldo.meira@fapcom.edu.br>
}

A obra de Vilém Flusser (1920-1991) chegou ao Professor Erick Felinto como nasce a reflexão filosófica, com espanto! Espanto pela singularidade de uma escrita e de uma forma de pensar. Flusser é muito mais do que um pensador das mídias e das tecnologias; sua obra, de temas diversificados, trata originalmente de problemas culturais, filosóficos e da arte. Diz nosso entrevistado: "encontramos nele uma combinação interessante entre pensamento técnico e pensamento 'imaginativo'. Acima de tudo, nossa atitude deve ser de abertura radical ao futuro como inteiramente aberto aos mais diferentes tipos de aventura humana”.

Elinaldo Meira: Como o senhor se aproximou da obra de Vilém Flusser? Seria possível delinear aquilo que na Filosofia se categorizaria como "espanto"?

Erick Felinto: Aproximei-me de Flusser na época do início do doutorado em Letras, que fiz em parte na UERJ e, em parte, na Universidade da Califórnia. Na UERJ, tomei contato com um texto de Flusser sobre Kafka, que havia sido publicado nos Cadernos do Mestrado, um empreendimento realizado pelos próprios alunos do curso. Antes disso, tinha apenas ouvido falar vagamente de Flusser e seu pensamento sobre a fotografia. A leitura do texto foi impactante, pois descobri em Flusser um modo de pensar extremamente singular, original, ousado. Muitos anos depois, estudando teoria da mídia alemã, fui para Berlim, trabalhar sob a supervisão de Siegfried Zielinski, que era então o diretor científico do Arquivo Flusser. Em contato com todos os materiais disponíveis no arquivo, o pensamento de Flusser rapidamente acabou absorvendo quase toda minha atenção, e fui percebendo o papel importante que ele teve no meio cultural alemão no qual se formou a nova teoria da mídia. Com todas as críticas que já se fizeram a Flusser, e com todos os equívocos que sua obra podia conter, percebi que suas relações com autores como Friedrich Kittler ou Zielinski eram fundamentais, de modo que havia nele algo de antecipatório, de quase até profético, eu diria. Finalmente, a partir de 2012 comecei a reparar um certo "renascimento" de interesse por Flusser, via uma série de traduções de sua obra ao inglês, em boa parte fomentada pelo Arquivo. Neste sentido começou a me interessar a proposta de traçar relações entre ideias de Flusser e de outros pensadores mais recentes nos campos da filosofia, da teoria cultural e da estética. Eu creio que se poderia dizer que meu interesse por Flusser começou com o "espanto", como deve começar toda filosofia, segundo Aristóteles. Nesse caso, o espanto 
com a singularidade da escrita e da forma de pensar.

Elinaldo Meira: $O$ que decorreu deste "espanto" em termos de dúvida, questionamentos, investigação?

Erick Felinto: Minha investigação focou-se menos em Flusser, na verdade, do que nas possibilidades de lê-lo a partir de olhares mais contemporâneos. Minha meta é menos ser "fiel" a Flusser do que trazê-lo para o presente, repensá-lo, colocá-lo em confronto com outros mundos e questões. Particularmente interessam-me mundos que foram abertos também por autores como Kittler, Siegert, Ernst, Parikka, que normalmente são associados à etiqueta "teoria da mídia alemã".

Elinaldo Meira: Em publicação da edição da revista Zum, do Instituto Moreira Salles, de maio de 2017, há a seguinte chamada: "Revolucionário, Flusser antecipou questões sobre o papel da imagem nos dias de hoje". O senhor crê nesta alcunha "revolucionário"? O que promove a importância, ou um diferencial de Flusser dentre os teóricos dos signos?

Erick Felinto: Esses termos geralmente dizem pouco. Mas eu confesso apreciar o epíteto de "profeta", já utilizado algumas vezes para o filósofo, não só por fazer parte da tradição judaica na qual Flusser estava inserido, mas também porque Flusser tem uma visão penetrante do futuro. É menos, contudo, o futuro material, eu diria, do que uma percepção profunda do espírito do tempo e das possibilidades que poderíamos abrir a partir de nosso relacionamento com a técnica. Eu creio que Flusser queria ser um "inventor de futuros", de modo que poderia ser chamado não apenas de visionário ou profeta, mas também de um fazedor de devires. Uma das coisas que mais me impressionou nele foi sua obsessão com octópodes, muitas vezes caracterizados em seus textos como seres alienígenas. Espanta-me hoje ver que o interesse por moluscos alcançou uma dimensão impressionante no domínio da ciência (a quantidade de livros publicados sobre o tema nos últimos anos é significativa). Não somente isso, a figura do octópode como "alienígena" de inteligência expressiva vem sendo também trabalhada nos discursos da ciência, de modo que aí temos um caso claro do caráter profético do pensamento flusseriano.

Elinaldo Meira: Haveria uma certa apropriação e leitura simplista dos conceitos sobre os quais Flusser trabalhou, dentre eles o de "imagens técnicas"? Perdoe-me se a pergunta também possa soar simplista, mas a obra de Flusser não poderia estar sendo usada para dar nomes e respostas a questões atuais por não querermos nos estudos de comunicação nos voltar às pautas antes de Flusser?

Erick Felinto: $\mathrm{O}$ que muita gente talvez ainda não tenha percebido a respeito de Flusser é que ele era muito mais que um pensador da mídia ou da tecnologia. Suas reflexões sobre problemas culturais e filosóficos da humanidade, assim como nossa relação com a arte me parecem em geral mais interessantes do que a maioria das coisas que Flusser disse a respeito da comunicação e dos meios. É impressionante, por outro lado, o quanto Flusser é pouco estudado em nossos cursos de teoria da comunicação. Na Alemanha, ele é figura fundamental de quase todo bom manual de 


\section{Suas reflexões sobre problemas culturais e filosóficos da humanidade, assim como nossa relação com a arte me parecem em geral mais interessantes do que a maioria das coisas que Flusser disse a respeito da comunicação e dos meios.}

teoria da mídia. Na verdade, é visto como um dos "pais" da reflexão contemporânea a respeito de comunicação e cultura. Esse esquecimento tem algo a ver com nossa tradição bacharelesca, que valoriza títulos e um tipo de pensamento inteiramente adequado a moldes acadêmicos. Flusser não se encaixa nisso. Todavia, existem elementos de uma espécie de "ambiência" cultural tipicamente brasileira em seu pensamento, $\mathrm{e}$ acho que essa é uma questão que ainda merece bastante exploração na sua obra.

Elinaldo Meira: Vilém Flusser nos oferece em suas obras a perspectiva de uma determinada forma de "ecologia comunicacional" (aqui é uma alusão que faço às ideias de Vicente Romano, pensador espanhol), embora, ou ainda que, na maior parte das situações esta "ecologia" parta da observação de que somos "funcionários" de um universo criado por imagens técnicas, que nos põem ausentes dos processos midiáticos. Como ser sujeito do processo? Onde (ou quando) em Flusser poderíamos identificar chaves de leitura para sonharmos com autonomia diante das mídias ou das políticas de comunicação?

Erick Felinto: Ainda que ele tenha notado a enorme dificuldade de sair da posição do funcionário, Flusser sugeriu ideias importantes para encontrarmos formas criativas e ativas de lidar com as tecnologias em sua ecologia midiática. Mesmo nos primeiros trabalhos, mesmo na Filosofia da caixa preta, ele nos dá indicações valiosas. Uma educação para os meios seria, por exemplo, um elemento importante. Nesse ponto, ele e Kittler convergem parcialmente. Deveríamos ter uma formação mais técnica para poder penetrar na caixa preta e entender os "textos" a partir dos quais operam nossos aparatos técnicos. Além disso, sua maior aposta se dava no uso artístico, criativo e aberto das tecnologias de modo a evitar formas congeladas. Lidar ludicamente com o aparato, explorar seus limites, ousar, são pontos importantes de sua reflexão. Desse modo, encontramos nele uma combinação interessante entre pensamento técnico e pensamento "imaginativo". Acima de tudo, nossa atitude deve ser de abertura radical ao futuro como inteiramente aberto aos mais diferentes tipos de aventura humana.

Elinaldo Meira: Pensemos nas superfícies de nossos celulares, tablets etc., sobre as quais deslizamos nossos dedos diariamente e, me parece, ainda muito mais neste período de quarentenas impostas pela pandemia de coronavírus. Uma camada nos lança a outra, e seguimos na crença de que a próxima nos revelará algo melhor, ou quando, do contrário, mais impactante, mais revelador. Quais são as limitações que essas superfícies nos impõem ao acessar esse mundo codificado? 
Erick Felinto: Elas são simultaneamente nossa forma de acesso principal ao mundo tecnológico, mas também aquilo que por vezes limita nossa capacidade de lidar com ele, pois a interface é a camada que nos oculta o hardware, o qual na maioria das vezes não dominamos. A interface pode ser ao mesmo tempo um caminho criativo ou uma janela transparente por meio da qual não aprendemos nada de novo.

Elinaldo Meira: Em louvor do espanto, pequena mas empolgante reflexão de Flusser, inicia-se com a citação de Camus, ao recordar de $O$ mito de Sísifo, com uma pergunta entendida como fundamental: "Por que não me mato?". Decorre desta pergunta, nesse artigo de Flusser, apontamentos que vão tratar de desapontamentos irrestritos com a vida. Como forma de lidar com a pergunta, e no intuito de criar um discurso dialético, Flusser recorre àquilo que ele chama de o "homem primordial", um ser mítico, marcado pelo espanto, envolto em medos; dessa forma, em oposição à citação de Camus, a pergunta desse homem primordial é "como sobreviver?". Volto um pouco ao que tratamos na primeira pergunta, quanto à questão "espanto": como ainda deixarmo-nos espantar em tempos contemporâneos? Como fazer do espanto uma forma de pleitear a vida e não a morte, tendo em vista a configuração de desprezo da parte do governo federal brasileiro pela imprensa, pelas questões da área da saúde pública, pelas questões das lutas sociais?

Erick Felinto: Flusser tem muitos momentos de pessimismo, mas me parece, na maior parte do tempo um otimista. É interessante acompanhar essas flutuações em seu pensamento. Eu me interesso particularmente pelos pessimistas, pela ideia de que a consciência é uma tragédia que se abateu sobre a espécie humana. Nesse sentido, o livro de Thomas Ligotti, The conspiracy against the human race, é um dos trabalhos mais interessantes e divertidos sobre essa perspectiva absolutamente sombria da existência. Acho o pessimismo um instrumento importante para evitar a imbecilidade, conquanto ele não leve ao desespero completo. No campo da comunicação, hoje, parece-me que o pessimismo está fora de moda e multiplicam-se os discursos de que devemos aceitar alegremente as mudanças que a tecnologia nos traz. Certo, não podemos negar os tempos e retornar ao passado, adotar uma atitude ludita. Mas ao mesmo tempo, esse otimismo excessivo, que pode ser encontrado, por exemplo, num autor muito apreciado aqui, Pierre Lévy, parece-me responsável em parte por algumas das tragédias que se abateram sobre nós nos últimos tempos. Em Vampyroteuthis infernalis, Flusser não supera certo estado de ambiguidade ao lidar com as transformações tecnológicas da sociedade. $\mathrm{Na}$ alegoria de seu personagem, encontramos tanto potências libertárias como os perigos do nazismo. Hoje vivenciamos o retorno de algo que considerávamos morto, mas parece renascer como um zumbi. Esse reaparecimento de tendências fascistoides em nível global nos convoca a ler pensadores como Walter Benjamin e Flusser, que agora estão se tornando mais atuais que nunca. As linhas finais de Vampyroteuthis infernalis são muito interessantes: Flusser aponta uma emergência progressiva desse estranho octópode alegórico e menciona diversas formas de 


\section{No campo da comunicação, hoje, parece-me que o pessimismo está fora de moda e multiplicam-se os discursos de que devemos aceitar alegremente as mudanças que a tecnologia nos traz.}

manifestação, por exemplo, nas "ideologias sangrentas nos programas políticos da dita 'direita"' (também não absolve a esquerda, ao criticar a ideia de revolução permanente). Que as tecnologias possam ser usadas como propagadoras de fake news, de discursos de ódio, de conservadorismo radical é algo que hoje sabemos muito bem. É nesse sentido que a dimensão sombria do pensamento flusseriano e certo pessimismo filosófico me interessam. Não para levar à inação, mas para buscar caminhos alternativos e estarmos conscientes dos perigos do entusiasmo tecnológico.

Elinaldo Meira: O senhor tem importantes parcerias que nos possibilitam acessar um saber sobre a obra de Vilém Flusser. Dentre estas estão o trabalho como parceiro da Universität der Künste Berlin, sob a supervisão de Siegfried Zielinski, na produção do DVD We Shall Survive in the Memory of Others, contendo as últimas entrevistas dadas por Flusser, e ainda conta, dentre suas atividades, a participação na elaboração do Dicionário Vilém Flusser (Flusseriana), publicado nos Estados Unidos (Univocal) em 2015. O senhor poderia nos falar um pouco de cada uma destas produções? Elas estão acessíveis no Brasil?

Erick Felinto: Elas infelizmente não estão diretamente disponíveis aqui. Eu nem sei se o DVD ainda existe ou se está esgotado, mas reúne importantes palestras e entrevistas de Flusser no exterior. O livro, porém, pode ser comprado pela Amazon, creio. Trata-se de uma obra importante, já que é o primeiro dicionário trilíngue (português-alemão-inglês) do pensamento de Flusser. Como toda obra coletiva é um pouco desigual, mas ainda assim ferramenta fundamental para todo estudioso de Flusser. Além disso, acabo de traduzir um texto para o inglês que será publicado numa coletânea importante, Understanding Flusser, understanding modernism, com ensaios a respeito da atualidade do pensador (editado pelo norte-americano Aaron Jaffe e outros estudiosos). No momento trabalho em um livro sobre Flusser (escrito em inglês, mas que, em seguida, gostaria de publicar no Brasil) propondo uma interpretação global de seu pensamento a partir de Vampyroteuthis infernalis e do que tenho chamado de “imaginário marítimo”. Acho que Flusser ainda vai dar muito o que falar nos próximos anos, a julgar pelo crescente aumento de referências a ele que autores como Eugene Thacker, Katherine Hayles ou John Durham Peters têm apresentado em suas obras. Eu diria que este é um momento interessante para se pensar com Flusser (mais do que propriamente tornar-se um "especialista" em Flusser). E eu espero que o Brasil saiba agora acolhê-lo, já que o resto do mundo para fazê-lo de forma decidida. Infelizmente, nossa condição periférica ainda parece condenar-nos a ler os nossos somente depois de obterem reconhecimento fora daqui. 


\section{Entrevista: Flusser com espanto • Erick Felinto}

Data de recebimento: $30 / 05 / 2020$

Data de aceite: 01/06/2020

Dados dos autores:

\section{Erick Felinto de Oliveira}

http://lattes.cnpq.br/2018614878087334

Doutor em Letras pela Universidade Estadual do Rio de Janeiro (UERJ) com a tese Silêncio de Deus, silêncio dos homens: resistências míticas, teológicas e gnósticas na literatura moderna. Professor na Universidade Federal do Rio de Janeiro. Bolsista de Produtividade em Pesquisa do CNPq - Nível 2.

\section{Elinaldo da Silva Meira}

http://lattes.cnpq.br/0816849762400016

Doutor em Artes pela Universidade Estadual de Campinas (Unicamp). Professor na Faculdade Paulus de Tecnologia e Comunicação. Realiza pesquisa pós-doutoral junto ao programa de pós-graduação em Comunicação da Universidade Federal do Ceará - UFC. 


\section{A COMUNICAÇÃO QUE NÃO VEMOS}

\section{A comunicação} que não vemos

Lucrécia D'Alessio Ferrara

Este livro busca discriminar as dimensōes da comunicaçāo que interferem na constituiçāo política das transformaçōes sociais, com suas consequências. 0 trabalho poderá atrair a atençāo e alimentar a reflexāo de todos aqueles que se interessam pela dimensāo cognitiva do exercício político e se manifesta na atividade profissional de comunicólogos, filósofos, sociólogos, historiadores, geógrafos, urbanistas, arquitetos e artistas.

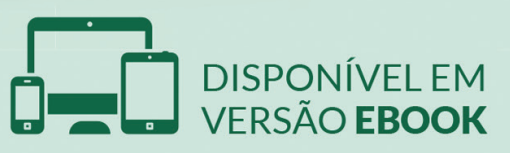


